\title{
Clinical study of visual field defects (VFD) in traumatic brain injury (TBI)
}

\author{
Tanushree $\mathbf{V}^{1}$, Sanjana Singh $\mathbf{R}^{2 *}$ \\ ${ }^{\mathbf{1}}$ Assistant Professor, ${ }^{2}$ Junior Resident, Dept. of Ophthalmology, Bangalore Medical College Hospital and Research Institute, Bangalore, \\ Karnataka, India \\ *Corresponding Author: Sanjana Singh $\mathbf{R}$ \\ Email: singh11sanjana@gmail.com
}

\begin{abstract}
Purpose: To determine the frequency of occurrence of visual field defect in a visually symptomatic patients with traumatic brain injury. Materials and Methods: A study was conducted at our institution on 40 patients with history of traumatic brain injury. Study was for a duration of one year from june-2018 to May-2019. Patients with detailed clinical information were included and was subjected to visual field analysis.

Results: Out of 40 cases, 32(80\%) were males and 8(20\%) were females. Age distribution varied from 10-62 years, with $18-45$ years being most common. $16(40 \%)$ patients had one of the targeted defect. Of which, 8(50\%) had scattered scotomas, 3(18\%) had Right \& $3(18 \%)$ had Left homonymous hemianopia, $2(12 \%)$ had bi-temporal hemianopia with chiasmal injury. Most frequent defects in the TBI were scattered scotomas next to homonymous hemianopia

Conclusion: Uniqueness of this study is that, it reports frequency of visual field defect in traumatic brain injury. Most were motor vehiclerelated, younger male patients. Findings should alert and make one aware of the adverse effects on quality of life and rehabilitation.
\end{abstract}

Keywords: Visual field defects (VFD), Traumatic brain injury (TBI).

\section{Introduction}

Visual field deficits may commonly follow head trauma. The afferent and efferent visual systems are susceptible to injury from a variety of mechanisms. These patients can be a diagnostic and therapeutic challenge, in large part secondary to the frequently vague nature of their visual complaints and their coexistent neurologic deficits. ${ }^{1}$

Traumatic brain injury is frequently associated with ophthalmic manifestations and consequent morbidity. Many of the ophthalmic findings are often ignored and hence present much later to specialist neuro-ophthalmic clinics. ${ }^{2}$

Homonymous hemianopia coupled with visual neglect is generally accepted as the most common type of visual field defect following traumatic brain injury.

This study emphasize the Clinical correlation of ophthalmic finding in early localization of the site of injury, ongoing assessment, management, rehabilitation and further prognosis of the patient with traumatic brain injury.

\section{Materials and Methods}

A Prospective study of 40patients with history of traumatic brain injury seen between April 2018 to May 2019 in the out patient department at Bangalore Medical College and Research Institute. This study was performed after obtaining 'permitted to study' by ethical committee.

All patients after taking an informed consent, underwent a standardized neuro-ophthalmic history and examination with detailed clinical information, which included Age, Sex of the patient, time of injury, types of visual field defects, location of lesion were recorded. Visual acuity recorded with snellens chart, refraction done, detailed anterior segment evaluation under slit lamp and detailed posterior segment evaluated to look for any pathology.

In our study visually symptomatic patients with history of traumatic brain injury was included. Patients with space occupying lesions, Optic neuropathy due to other causes like infectious, inflammatory, toxic, vascular, dietary and neoplastic, Glaucomatous field defect were excluded.

Visual fields were tested by confrontation test and Humphrey automated perimeter.

The association between the visual field defect and ocular findings, neuro-deficit and the final outcome of the patient was evaluated.

\section{Results}

The total number of cases in our study were 40 individuals with history of traumatic brain injury, out of which 32 $(80 \%)$ were males and 8 patients $(20 \%)$ were females.Age distribution in our study varied from 10-62 years, with most number of cases were reported from the age group of $18-45$ years - being the most common.

In this sample of 40 patients, 16patients (40\%) patients had one of the targeted defect. Out of which, 8 patients (50\%) had scattered scotomas, 3 patients (18\%) had Right \& 3 patients (18\%) had Left homonymous hemianopia ( $\mathrm{HHm})$, 2 patients (12\%) had bi-temporal hemianopia with chiasmal injury. The most frequently affected visual field defect in TBI was found to be scattered scotomas followed by homonymous hemianopia.

Various mode of injury presented to us were: Motor vehicle accident which accounts to nearly $75 \%$ of all cases being the most common type of injury. Followed by blunt trauma (15\%), self fall and projectile object injury accounted to 5\%each in our study.

The data regarding the numeric and percentage distribution of the age (Fig. 1), sex distribution (Fig. 2) and targeted visual field defects for all subjects are presented in Fig. 3. 


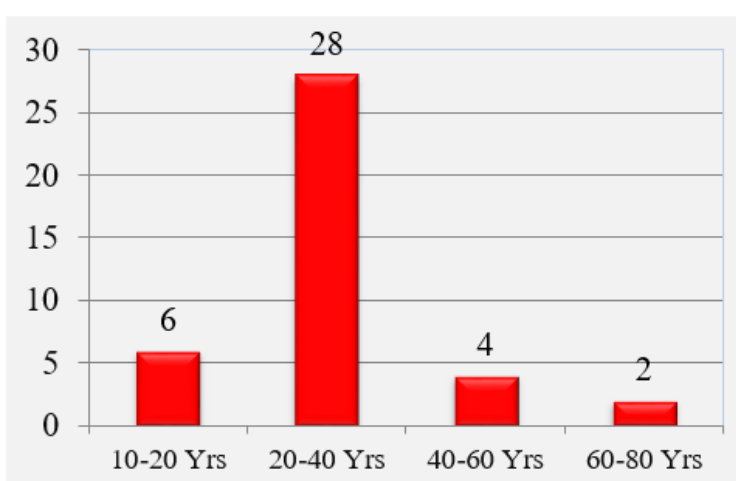

Fig. 1: Age distribution

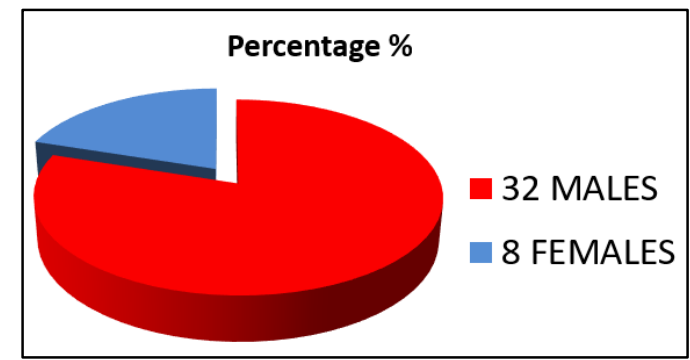

Fig. 2: Sex distribution in percentage

Case 1: 48yr old male patient with left sided homonymous hemianopia

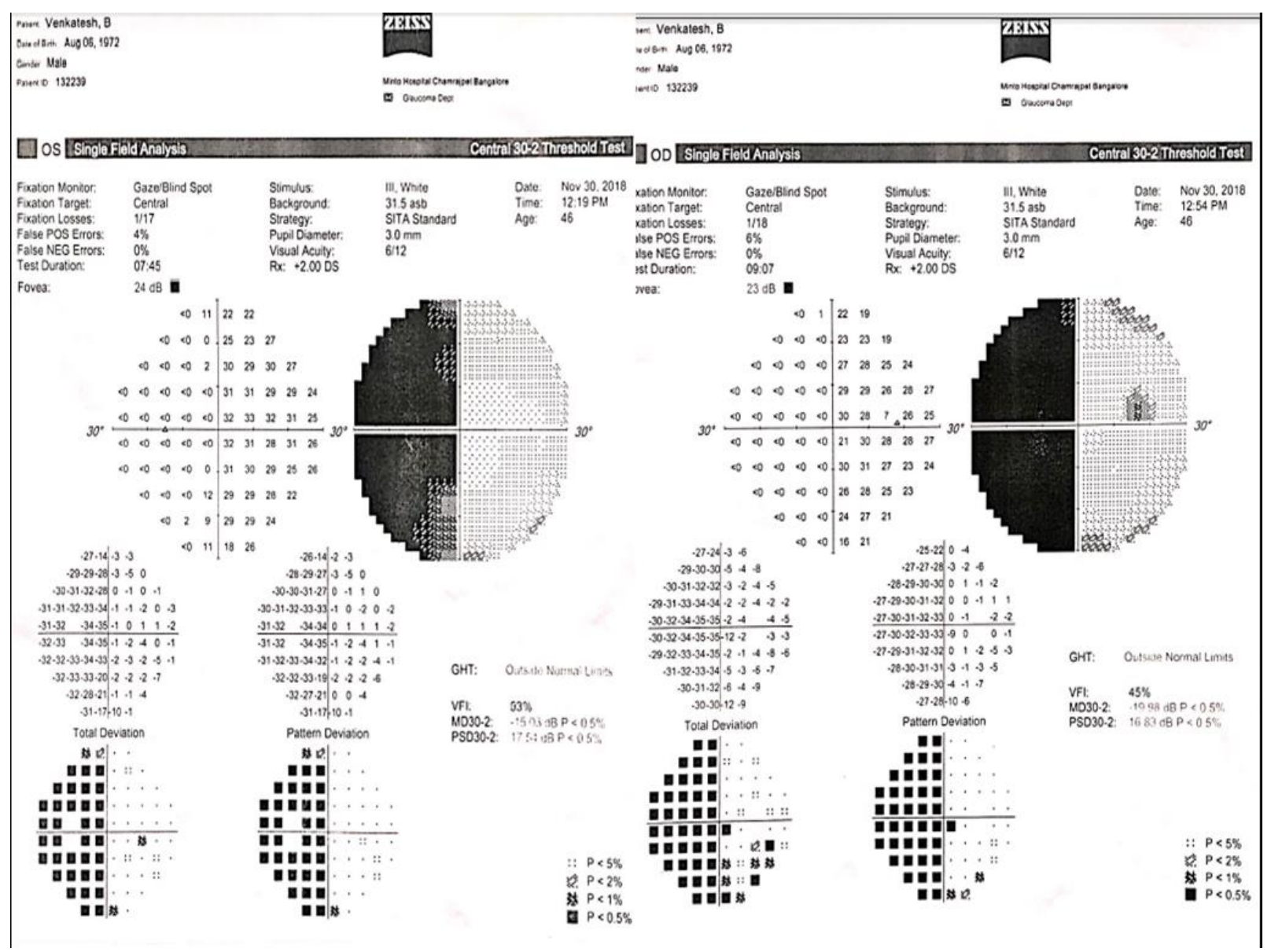


Case 2: 26yr old male patient with right sided homonymous hemianopia

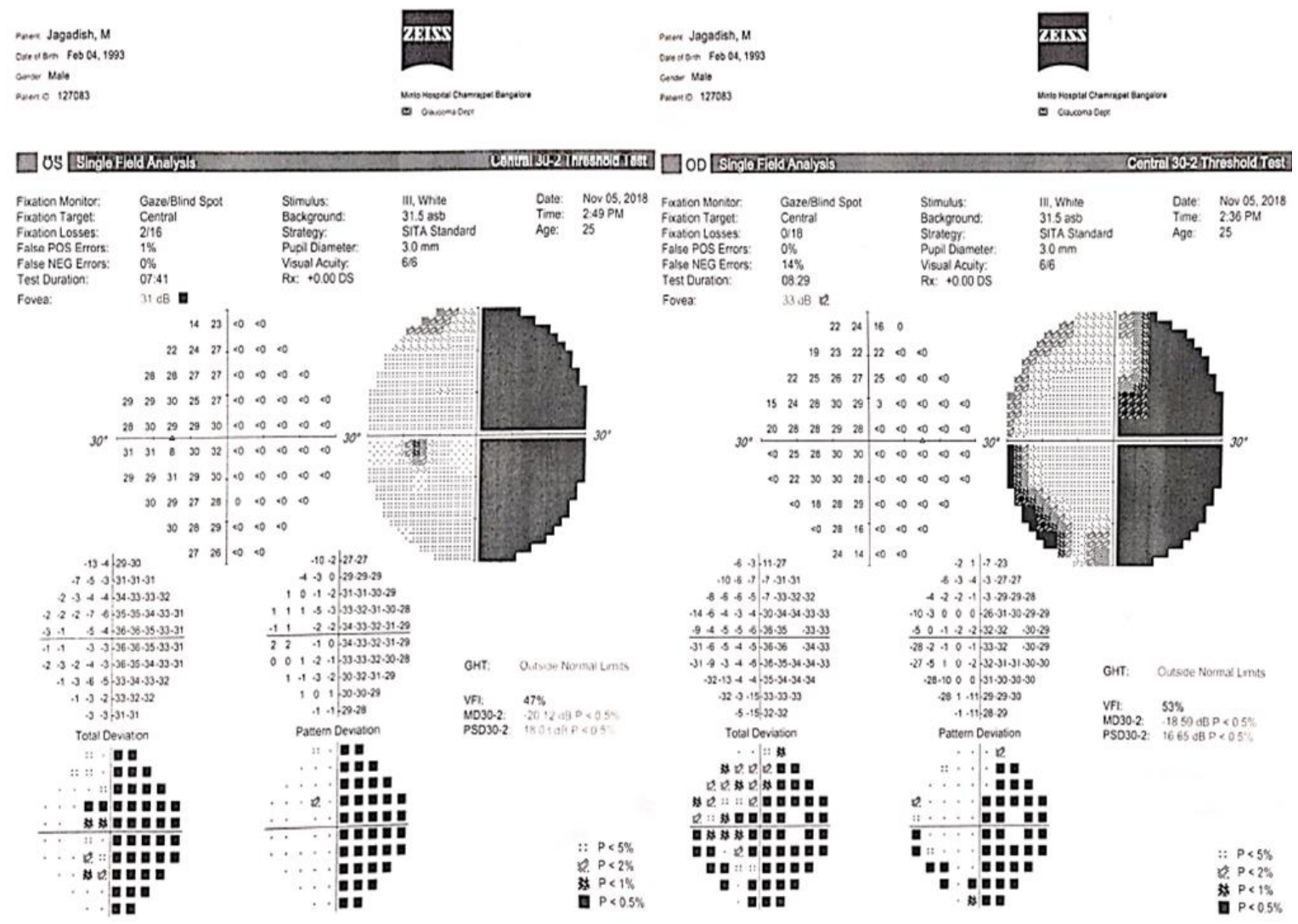

Case 3: 16 years old male patient with bitemporal hemianopia extending into bilateral infero-nasal quadrant

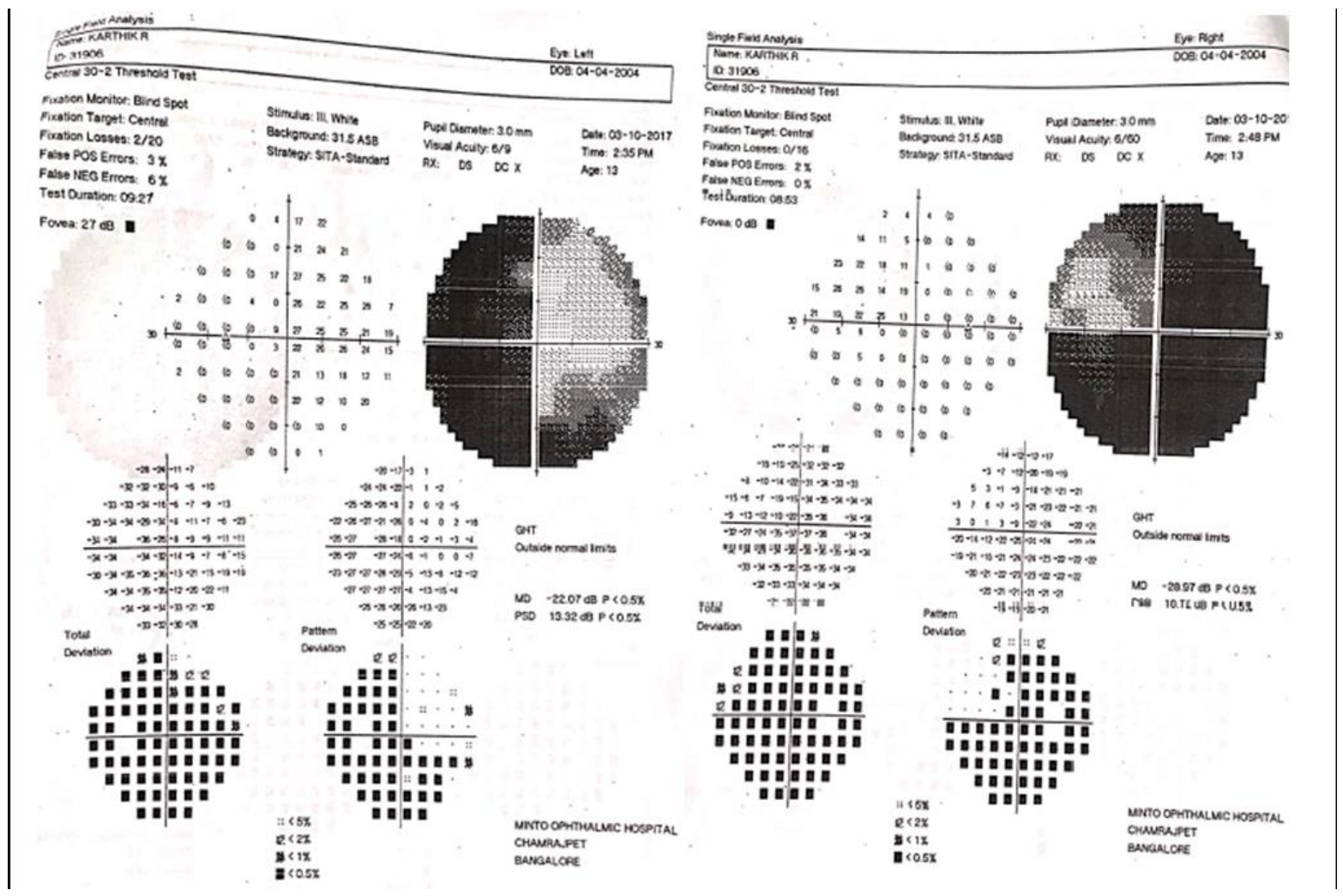


Case 4: 40 years old male patient with Bitemporal hemianopia

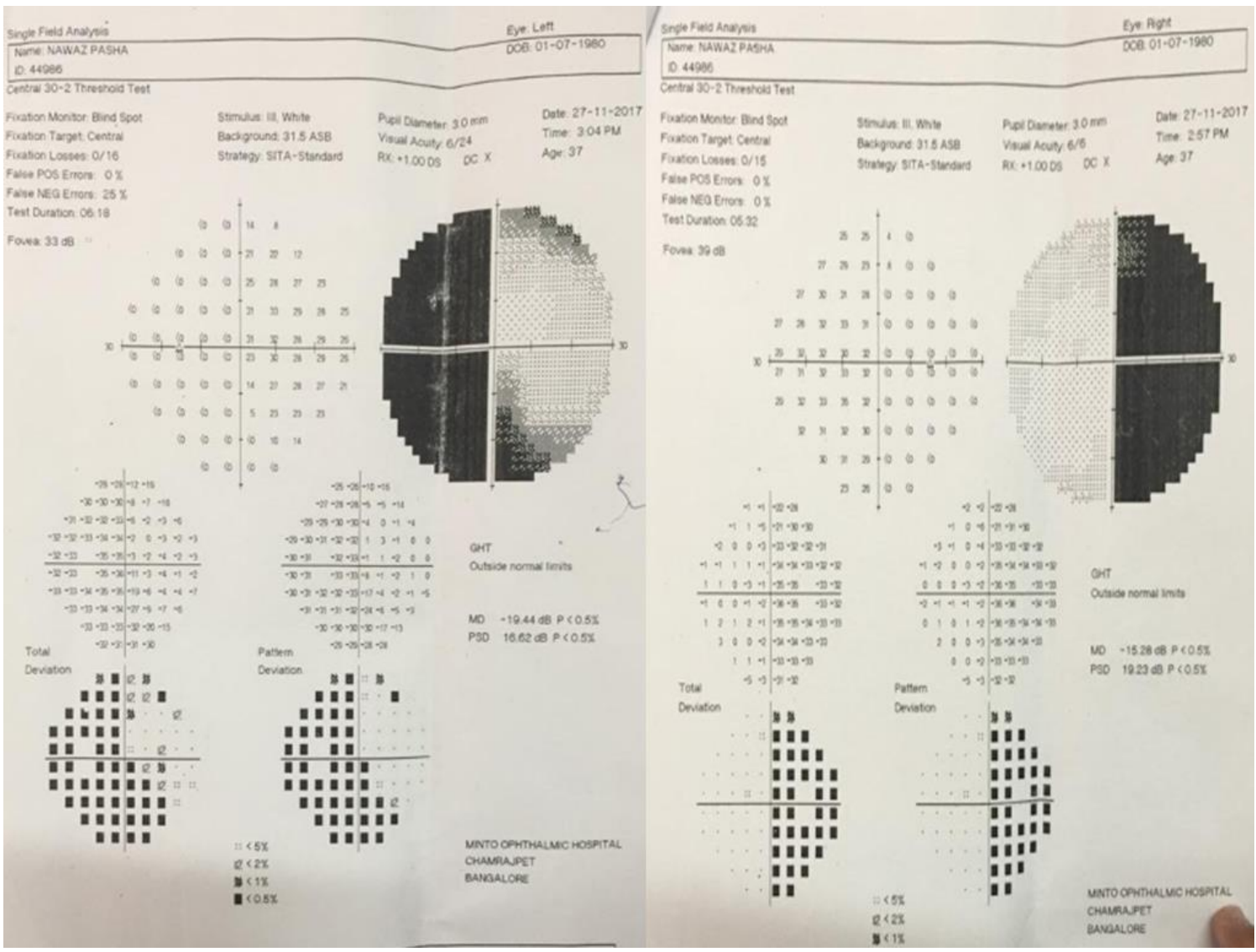

Case 5: Right eye Superior arcuate scotoma extending into inferior arcuate. Left eye early superior arcuate scotoma
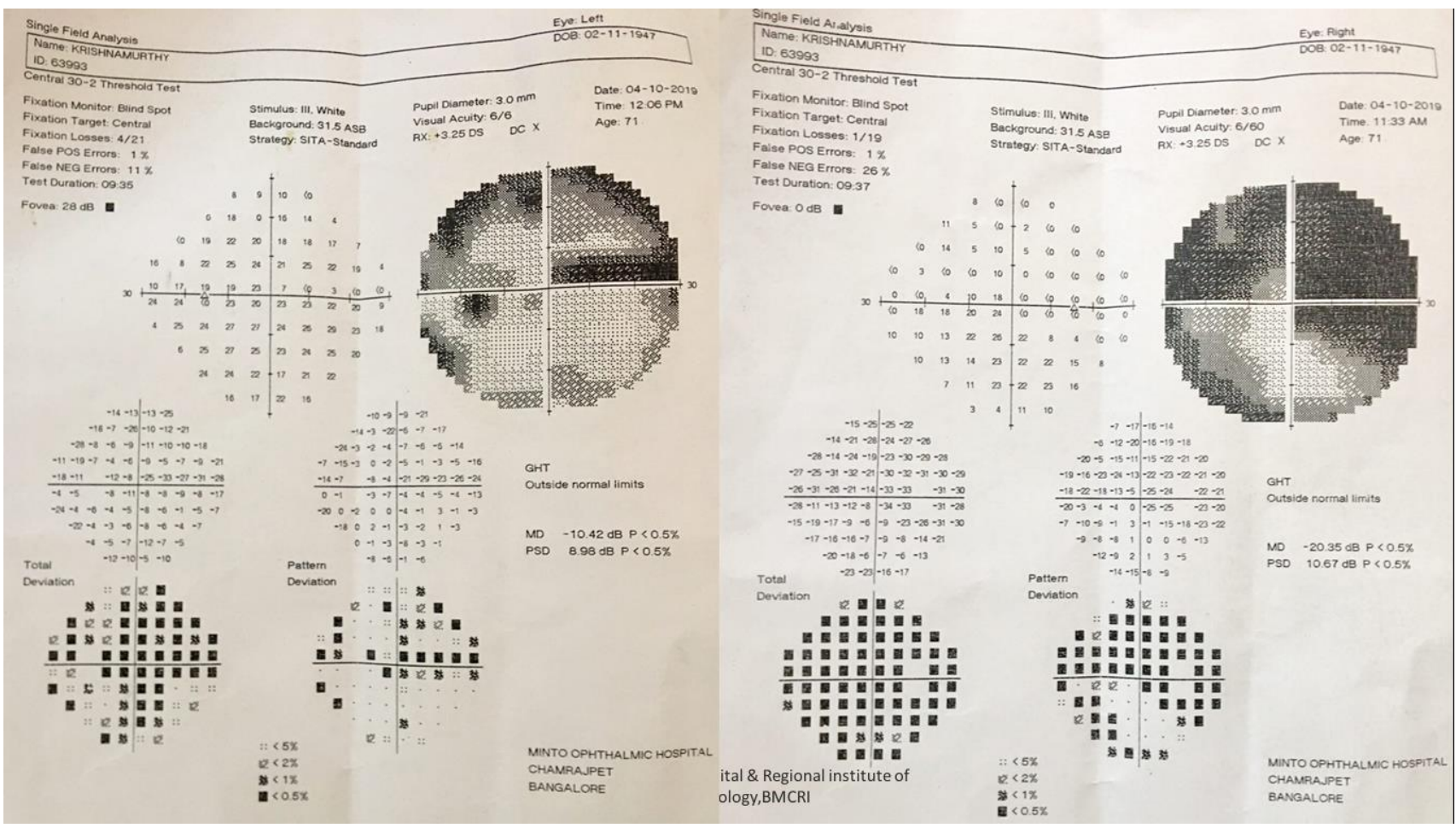
Table 1: Percentage of patients with visual field defect

\begin{tabular}{|l|c|c|}
\hline \multicolumn{3}{|c|}{ Frequency of occurrence of VFD in the total sample of TBI patients } \\
\hline TBI $(\mathrm{n}=40)$ & No of subjects with VFD & $\%$ of subjects with VFD \\
\hline
\end{tabular}

Table 2: 16 patients (40\%) patients had one of the targeted defect represented in the table

\begin{tabular}{|l|l|}
\hline Total no of patients & Type of visual field defect \\
\hline 8 & scattered scotomas \\
\hline 3 & Right homonymous hemianopia \\
\hline 3 & Left homonymous hemianopia \\
\hline 2 & bi-temporal hemianopia with chiasmal injury \\
\hline
\end{tabular}

\section{Discussion}

Various presentations of visual field defects may occur following TBI as a result of damage to any portion of the visual pathway from the visual cortex of the brain onward to the retina.

Defects may include constriction of the fields and either isolated or multiple scattered defects throughout the fields, with or without a generalized decrease in sensitivity. Lateralized field defects such as homonymous hemianopias may also occur with or without neglect, in which patients are fully unaware of objects located in space within the visual field defects. ${ }^{5}$

Symptoms of visual field defects include mobility issues (e.g., patients bumping into objects), reading diiculties and trouble locating items in tasks of daily living such as eating. Homonymous hemianopias create significant safety challenges, especially when associated with neglect and any activities that require an accurate awareness of one's surroundings. ${ }^{5}$ Screening for gross field defects by confrontation testing is useful, but more detailed evaluation with automated or Goldmann perimetry is essential to accurately localize and quantify any suspected defects. ${ }^{5}$

Visual field testing is critical in these populations, as well as ensuring visual fields are in consideration when evaluating quality of life and developing rehabilitation programs. Homonymous hemianopias have a major legal and financial impact because of their effects on driving, additionally, these deficits affect patient's quality of life such as reading and other tasks. ${ }^{4}$

Neuro vision Rehabilitation can be carried out by the following methods:

1. Lenses: Plus lenses to stabilise the vestibular ocular systems

2. Peli prisms: To locate objects outside the patient's visual field. Prisim is placed on the lens of the temporal field defect. Upper and lower are 40-57D press on prisms. These expand the field by 22 degree.

3. Binasals: Eliminates binocular confusion. ${ }^{6}$

\section{Conclusion}

Uniqueness of this study reports frequency of visual field defects in Traumatic brain injury. The most commonest was motor vehicle-related injury especially in the younger individuals who were predominantly male patients.
All these findings should alert and make one aware of the adverse effects on quality of life and rehabilitation. ${ }^{7}$ This Study emphasises the importance of early, systematic evaluation of all patients with traumatic head injury for homonymous hemianopia, as it is important for the functioning and rehabilitation of the patient.

\section{Source of Funding}

None.

\section{Conflict of Interest}

None.

\section{References}

1. Van Stavern GP, Biousse V, Lynn MJ, Simon DJ, Newman NJ. Neuro-Ophthalmic Manifestations of Head Trauma. $J$ Neuro-Ophthalmol. 2001;21(2):112-7.

2. Kulkarni AR, Aggarwal SP, Kulkarni RR, Deshpande MD, Walimbe PB, Labhsetwar AS. Ocular manifestations of head injury: A clinical study. Eye (Lond). 2005;19(12):1257-63.

3. Suchoff IB, Kapoor N, Ciuffreda KJ, Rutner D, Han E, Craig $\mathrm{S}$. The frequency of occurrence, types, and characteristics of visual field defects in acquired brain injury: A retrospective analysis. Optometry. 2008;79(5):259-65.

4. Bruce BB, Zhang X, Kedar S, Newman NJ, Biousse V. Traumatic homonymous hemianopia. J Neurol Neurosurg Psychiatry. 2006;77(8):986-8.

5. Suhr CL, Shust M, Prasad R, Wilcox DT, Chronister C. Recognizing TBI-related vision disorders; 2015.

6. Kapoor N, Suchoff IB, Ciuffreda KJ, Han E, Rutner D, Craig $\mathrm{S}$. Characteristics of visual field defects in acquired brain injury: A retrospective analysis. Investig Ophthalmol Vis Sci. 2008;49:451.

How to cite: Tanushree V, Singh SR. Clinical study of visual field defects (VFD) in traumatic brain injury (TBI). Panacea J Med Sci. 2020;10(1):21-5. 